\title{
Numerical study of the efficiency of integrating phase change material into a clay-straw wall in the Drâa-Tafilalet region (Errachidia Province)
}

\author{
Zaineb Ben Zaid ${ }^{1 *}$, Amine Tilioua ${ }^{1}$, Omar Ansari ${ }^{2}$, Ibtissam Lamaamar ${ }^{1}$, Moulay Ahmed \\ Hamdi Alaoui ${ }^{3}$ \\ ${ }^{1}$ Research Team in Thermal and Applied Thermodynamics (2.T.A.), Physics Department, Sciences \\ and Techniques Faculty Errachidia, Moulay Ismail University Meknes, B.P. 509 Boutalamine \\ Errachidia, Morocco. \\ ${ }^{2}$ Research Team in Thermal and Energy, ENSET, Mohammed V University, Avenue de l'Armée \\ Royale, B.P. 6207 Rabat-Instituts, Madinat Al Irfane, Rabat, Morocco. \\ ${ }^{3}$ Laboratory of Materials and Modification, Department of Physics, Faculty of Sciences, Moulay \\ Ismail University, B.P. 11201 Zitoune. 5000 Meknes, Morocco.
}

\begin{abstract}
The objective of this study is to evaluate the thermal performance of clay-straw walls of buildings integrating phase change materials (PCM). The influence of integrating different types of PCM in the envelope has been studied numerically in several studies. The optimal wall thickness with PCM integrated suitable for the climatic conditions of Errachidia has been studied. The heat balance equations for the different wall configurations are formulated and solved numerically under the same climatic conditions. The results obtained show that the integration of PCM in the clay-straw wall instead of the cement wall increases the heat flux density as a function of time by up to $80 \%$ based on the thermal properties of the PCM and the environmental conditions of the study.
\end{abstract}

\section{Introduction}

The use of renewable energies and the reduction of conventional energy consumption as a way of trying to improve environmental problems such as global climate change has become the main concern of the scientific engineering research that is currently being developed [1]. Countries need to orientate to renewable energy consumption in energy policies[2], [3]. In the same context, the use of phase change materials (PCMs) for thermal energy storage strategies in buildings can meet potential thermal comfort requirements when they are properly selected. A summary of the PCMs used and their respective properties are also presented[4]. Various researches have been carried out to study phase change problems and the effect of the heating and cooling conditions. Kaba et al. [5] developed an efficient numerical phase change model for modeling both the isothermal and non-isothermal phase change problems. El Idi et al.[6] studied numerically the effect of

* Corresponding author: benzaidzaineb@gmail.com 
cyclical heating and cooling conditions on phase change kinetics of paraffin-embedded in a metal foam. Meng et al.[7] proposed a new partial copper foam filler to improve the thermal performance of latent thermal storage units, which not only responded to the background of thermal utilization of solar energy but also occupied the low PCM position, which was in favor of ensuring thermal storage density. Systems studied are shown to be effective in reducing indoor temperature fluctuations and energy demand during cold seasons, as well as the ability to trigger load reduction [8]. Al-Absi et al.[9] investigated the potential of passive application of PCMs for the indoor environment of buildings in the warm-humid climate of Malaysia. In addition, the capacity of PCMs to reduce the maximum indoor air temperature of buildings naturally conditioned in a warm-humid climate region by storing night-time coolness is studied. There are different ways of integrating PCMs in buildings. Many previous experimental works show the integration of PCMs into wall systems via gypsum plasterboard. [10] [11], wall panels [12] [13], external bricks [14], [15] or in the interior of the insolation cavity [16] [17]. Other present PCM integration in floors [18]. Also there are some experimental and simulation researches on the optical and thermal performance of glazing units containing PCM [19] etc. We investigated experimentally [20] the integration of PCM (paraffin 21.7) in a clay-straw wall in order to reduce the energy consumption of buildings in the Drâa-Tafilalet Region (Errachidia Province), Morocco. The objective of this paper is to evaluate the effectiveness of using PCM in the building envelope in the Drâa-Tafilalet region (Province Errachidia). An evaluation of the effect of incorporating 4 different PCMs into a clay-straw wall in terms of reducing cooling needs is presented. And finally, a comparative study between clay-straw walls and cement walls is investigated.

\section{Materials and methods}

\subsection{The problem statement}

The wall studied in this paper is a clay-straw wall incorporating a PCM. The geometry of these walls is shown in Fig. 1. Four different PCMs are used, which differ mainly in their median melting temperature $T_{m}$ and composition as shown in Table 1.

(a)

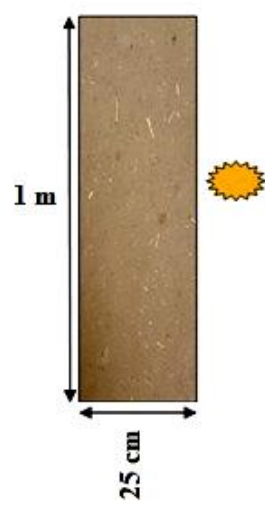

(b)

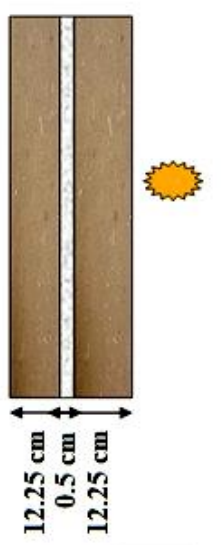

(c)

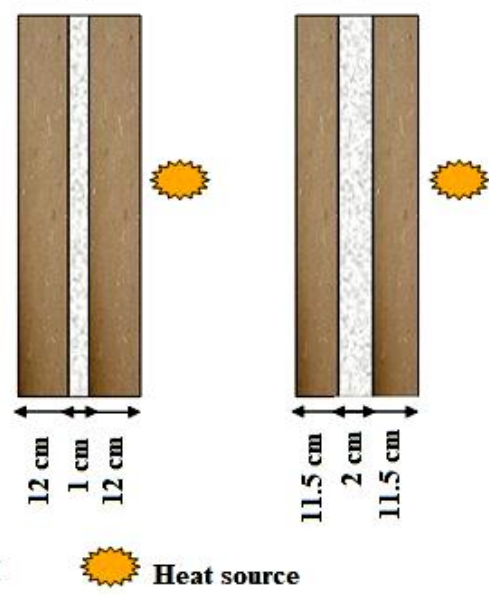

Fig. 1. The different wall configurations: (a) Wall without PCM, (b) Wall with $0.5 \mathrm{~cm}$ of PCM, (c) Wall with $1 \mathrm{~cm}$ of PCM, (d) Wall with $2 \mathrm{~cm}$ of PCM. 
Table 1. Thermophysical properties of the clay-straw and PCMs [21][22], [23][24][25]

\begin{tabular}{|c|c|c|c|c|c|c|c|c|}
\hline \multirow[t]{2}{*}{ Material } & \multirow{2}{*}{$\begin{array}{c}\text { median } \\
\text { melting } \\
\text { temperat } \\
\text {-ure }\left({ }^{\circ} \mathrm{C}\right)\end{array}$} & \multicolumn{2}{|c|}{$\begin{array}{c}\text { Thermal } \\
\text { conductivity } \\
\text { (W/m.K) }\end{array}$} & \multicolumn{2}{|c|}{ Density $\left(\mathrm{kg} / \mathrm{m}^{3}\right)$} & \multicolumn{2}{|c|}{$\begin{array}{c}\text { specific heat } \\
\text { capacity }(\mathrm{J} / \mathrm{kg} \cdot \mathrm{K})\end{array}$} & \multirow{2}{*}{$\begin{array}{c}\text { latent } \\
\text { heat of } \\
\text { fusion } \\
\text { Lf } \\
\text { (KJ/Kg) }\end{array}$} \\
\hline & & Solid & Liquid & Solid & Liquid & Solid & Liquid & \\
\hline Clay-straw & ---- & 0.28 & --- & 1537 & --- & 786 & --- & --- \\
\hline Cement & $\begin{array}{ll}--- \\
\end{array}$ & 1.153 & --- & 1700 & --- & 1000 & --- & --- \\
\hline $\begin{array}{l}\text { PCM 24 } \\
\text { (Paraffin) }\end{array}$ & 24 & 0.21 & 0.21 & 900 & 760 & 2100 & 2100 & 144 \\
\hline PCM 27 & 27 & 0.577 & 0.813 & 1710 & 1530 & 1751 & 2225 & 172.42 \\
\hline $\begin{array}{c}\text { PCM32 } \\
\text { (Capric-Acid) }\end{array}$ & 32 & 0.149 & 0.149 & 1004 & 886 & 2096 & 2088 & 152 \\
\hline $\begin{array}{c}\text { PCM 37 } \\
\text { (n-Eicosane) }\end{array}$ & 37 & 0.15 & 0.15 & 778 & 856 & 2010 & 2040 & 241 \\
\hline
\end{tabular}

\subsection{Numerical model}

\subsubsection{Hypotheses}

In order to evaluate the variations in temperatures and heat flows in clay-straw brick incorporating a PCM and in order to write the equations governing the physical problem to be solved, it is necessary to make a number of assumptions:

- The thermophysical properties of PCM are constant but may be different in the liquid and solid phases (conductivity, specific heat, and density).

- The material is assumed pure and the change of state takes place at a constant temperature $\mathrm{T}_{\mathrm{m}}$ (melting temperature).

- The problem is two-dimensional and transitory.

- $\quad$ Constant thermo-physical properties of the brick.

- $\quad$ PCM is homogeneous and isotropic.

- No humidity inside the brick, and therefore no heat source due to evaporation.

- Perfect contact between the PCM and the surfaces of the clay-straw layer

- Negligible convection in the liquid phase of the PCM.

- $\quad$ Narrow phase change temperature range $\left(1^{\circ} \mathrm{C}\right)$.

- PCM expansion is neglected and phase change is isothermal.

- $\quad$ No radiative exchange with the soil.

\subsubsection{Boundary and initial conditions}

The external wall surface receives solar radiation, which depends on the orientation (south) of the wall and time, and exchanges heat by convection with the outside air. The boundary condition at the external wall surface is as follow:

$$
\varphi_{e}=h_{e}\left(T_{e}-T_{w}(x=0, y, t)\right)+\alpha q_{s}(t) \quad \forall y \in[0, H]
$$

where the wall solar absorption coefficient is assumed to be $\alpha=0.6$ [23] and the outside convective heat transfer coefficient is assumed to be $h_{e}=25 \mathrm{~W} /\left(\mathrm{m}^{2}\right.$. K) [26].

All these boundary conditions are explicitly shown in Fig. 1

A convective boundary condition is applied to the internal surface of the wall under consideration, supposing that the inside temperature is $\mathrm{T}_{\mathrm{i}}=26^{\circ} \mathrm{C}[27]$ :

$$
\varphi_{i}=h_{i}\left(T_{i}-T_{w}(x=L, y, t)\right) \quad \forall y \in[0, H]
$$

where the inside convective heat transfer coefficient of the horizontal heat flow is assumed to be $h_{i}=7.69 \mathrm{~W} /\left(\mathrm{m}^{2} . \mathrm{K}\right)[26]$. 
The initial temperature of all wall configurations is assumed uniform for all layers:

$$
T_{w}(t=0, x, y)=25^{\circ} \mathrm{C} \quad \forall(x, y) \in\{[0, L],[0, H]\}
$$

All these boundary conditions are explicitly shown in Fig. 2

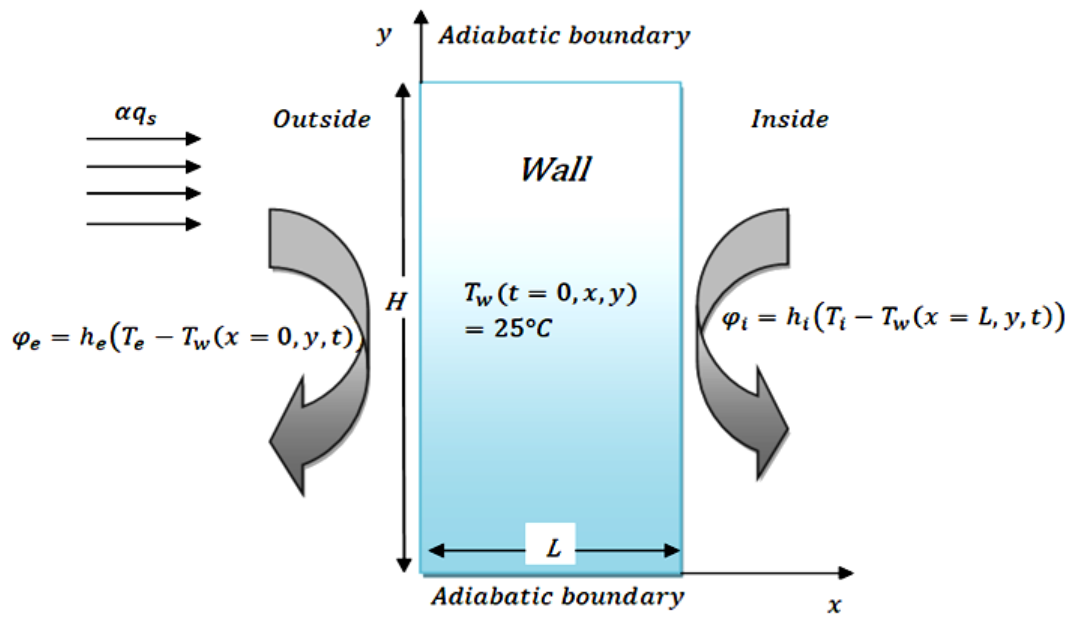

Fig. 2. COMSOL heat transfer model geometry, and boundary conditions.

\subsubsection{COMSOL multi-physic modeling}

The numerical method is based on the finite element method and uses the Galerkin approach [23] to discretize the Heat transfer equations. The external surface of the walls is horizontally oriented and subjected to solar radiation and ambient air convection in the Drâa-Tafilalet region. In order to avoid moving from one PCM phase to another in a short period in any finite element, a $\Delta \mathrm{t}=360 \mathrm{~s}$ time step was chosen for all the simulations of this study. The complete triangular mesh consists of 1644 domain elements and 139 boundary elements as shown in Fig. 3.

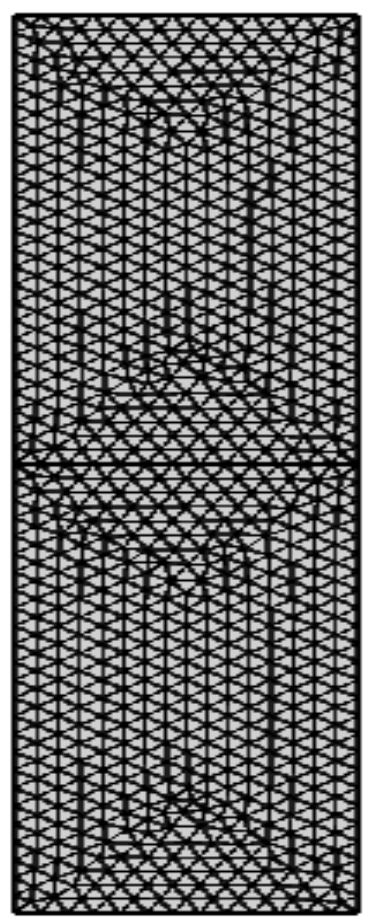

Fig. 3. Triangular mesh generation (1644 elements) 


\section{Results}

An analysis of the effect of integrating PCM with distinct median melting temperatures (24 ${ }^{\circ} \mathrm{C}, 27{ }^{\circ} \mathrm{C}, 32{ }^{\circ} \mathrm{C}$, and $37^{\circ} \mathrm{C}$ ) in clay-straw walls on the heat flux density and temperature at the inside wall surface is presented in summer weather conditions in the Drâa-Tafilalet region. The solar radiation and the outside ambient temperature of Errachidia are shown in Fig. 4 for days of July from 28 to 31 .

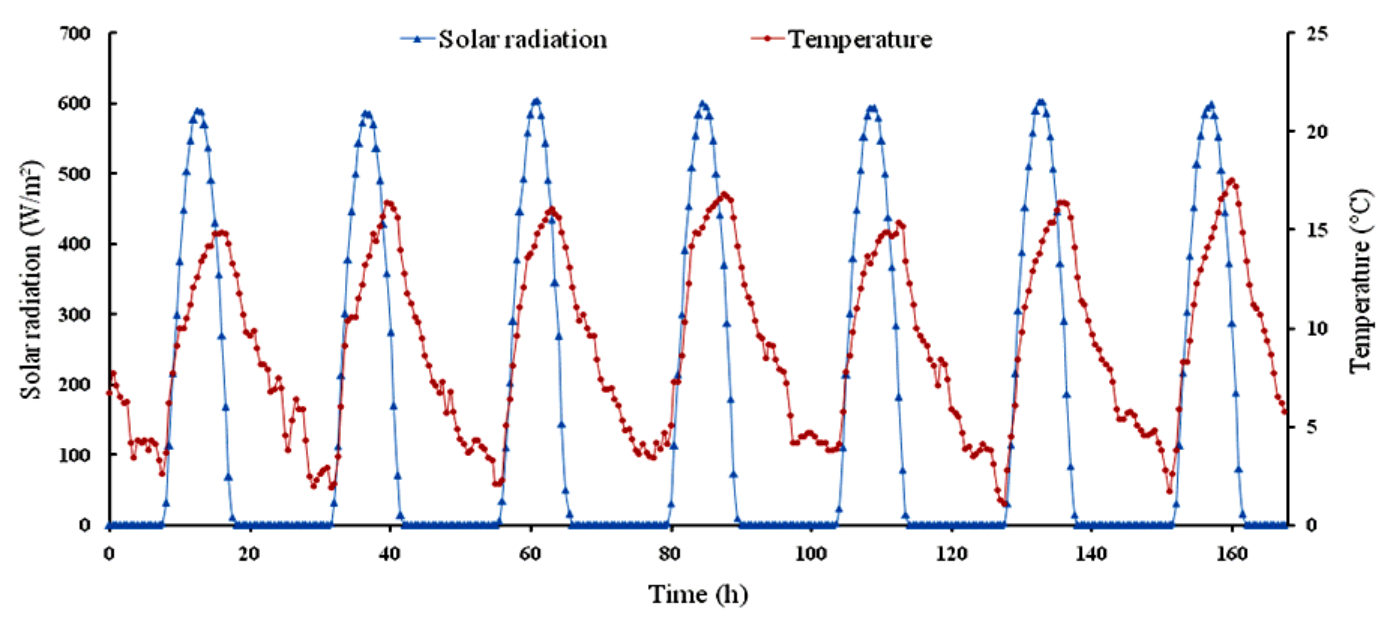

Fig. 4. Solar radiation (left axis) on vertical south walls and outside air temperature (right ax is) in Errachidia on 28-31 July

\subsection{Heat flux density at the internal surface of clay-straw walls}

In this section, the heat flux density is analyzed to choose the optimal PCM to the DraaTafilalet region. Four PCMs with distinct median melting temperatures $\left(24^{\circ} \mathrm{C}, 27^{\circ} \mathrm{C}, 32\right.$ ${ }^{\circ} \mathrm{C}$, and $37^{\circ} \mathrm{C}$ ) are integrated into a clay-straw wall and compared to another without PCM. Figure 5 present the heat flux density at the internal surface of walls integrating different thickness of PCMs layer. For layer thickness of PCM equal to $0.5 \mathrm{~cm}$ (fig.5-(a)), heat flux density follows the variations of external conditions except for the first day. In this one, it is clear that walls take heat from the exterior gradually because at $\mathrm{t}=0 \mathrm{~h}$ it is night. Then in the next day, the flux never cancels because the walls store the heat inside and release it at night. PCM 37 generates a higher flux than a clay-straw wall without PCM. Therefore, PCM 37 is a bad choice for this region. PCM 24 and PCM 27 have approximately the same heat flux density; they can reduce the heat flux up to $1.8 \mathrm{~W} / \mathrm{m}^{2}$ than clay-straw wall. PCM 32 has the minimum heat flux value in comparison to the other walls; it can reach a maximum difference equal to $3 \mathrm{~W} / \mathrm{m}^{2}$. It is shown that for the third and fourth day the peak of the heat flux density of PCM 32 is smaller than the other walls. For layer thickness of PCM equal to $1 \mathrm{~cm}$ (fig.5-(b)), similar behaviors in terms of heat flux density can be observed by comparing them to the results of the $0.5 \mathrm{~cm}$ thick layer. PCM 37 has the highest heat flux density in comparison with all walls. PCM 24 and PCM 27 can reduce the heat flux up to $1.2 \mathrm{~W} / \mathrm{m}^{2}$ than the clay-straw wall. PCM 32 has the smallest and most efficient heat flux density value compared to other walls; it can reach a maximum difference equal to $4 \mathrm{~W} / \mathrm{m}^{2}$. For a PCM layer thickness equal to $2 \mathrm{~cm}$ (Fig.5- (c)), some similar behaviors in terms of heat flux density can be noticed by comparing them to the results of the $0.5 \mathrm{~cm}$ and $1 \mathrm{~cm}$ thick layer. PCM 37 has the highest heat flux density of all the walls. PCM 24 can decrease heat flux by up to $2 \mathrm{~W} / \mathrm{m}^{2}$ compared to clay straw walls. This time PCM 27 has nearly the same density as the clay-straw wall. PCM 32 has the 
minimum and most efficient heat flux density value compared to other walls and can achieve a maximum difference of $5.3 \mathrm{~W} / \mathrm{m}^{2}$. Finally, in terms of the reduction of heat flux peak, the PCM with a $T_{m}=32{ }^{\circ} \mathrm{C}$ median melting temperature is efficient in the DrâaTafilalet region.

a)

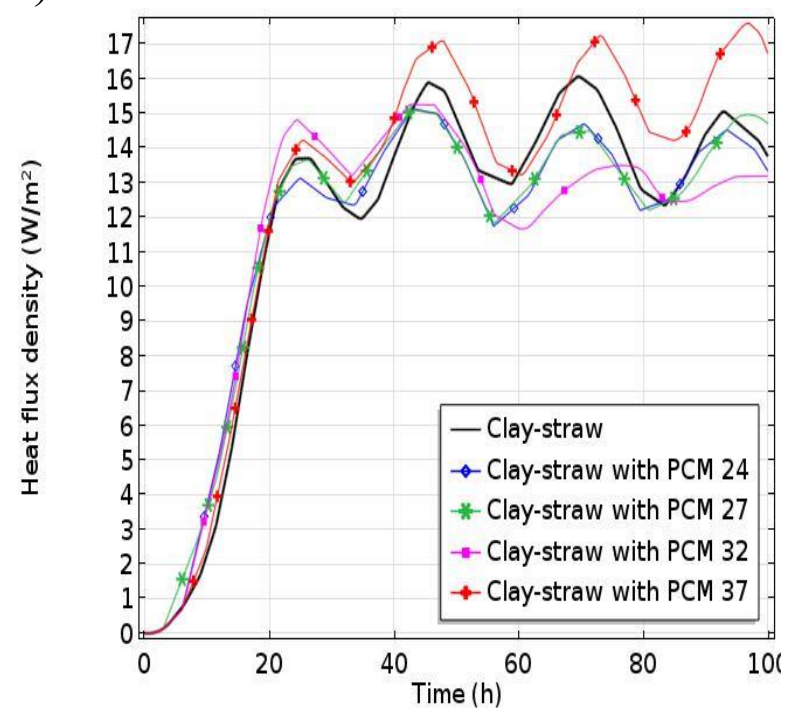

b)

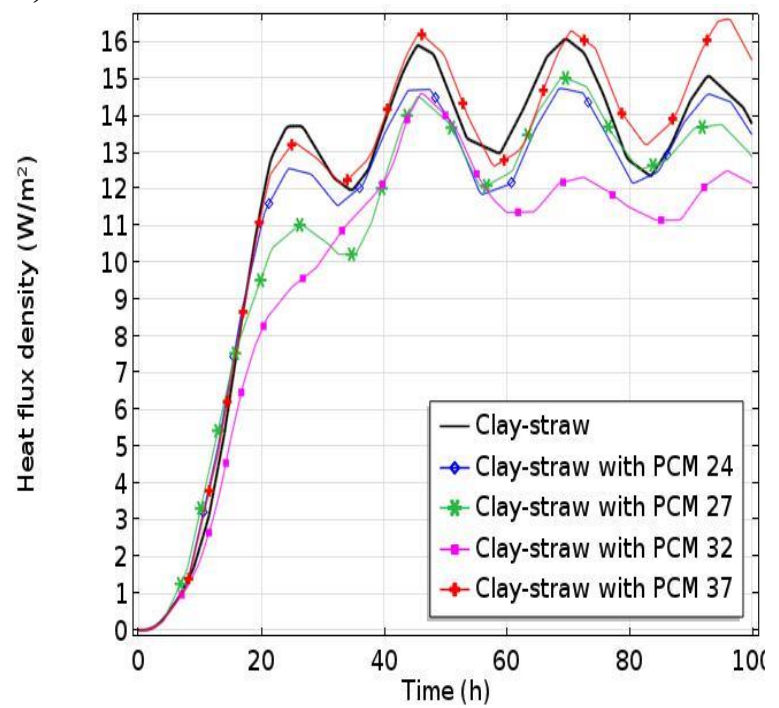

c)

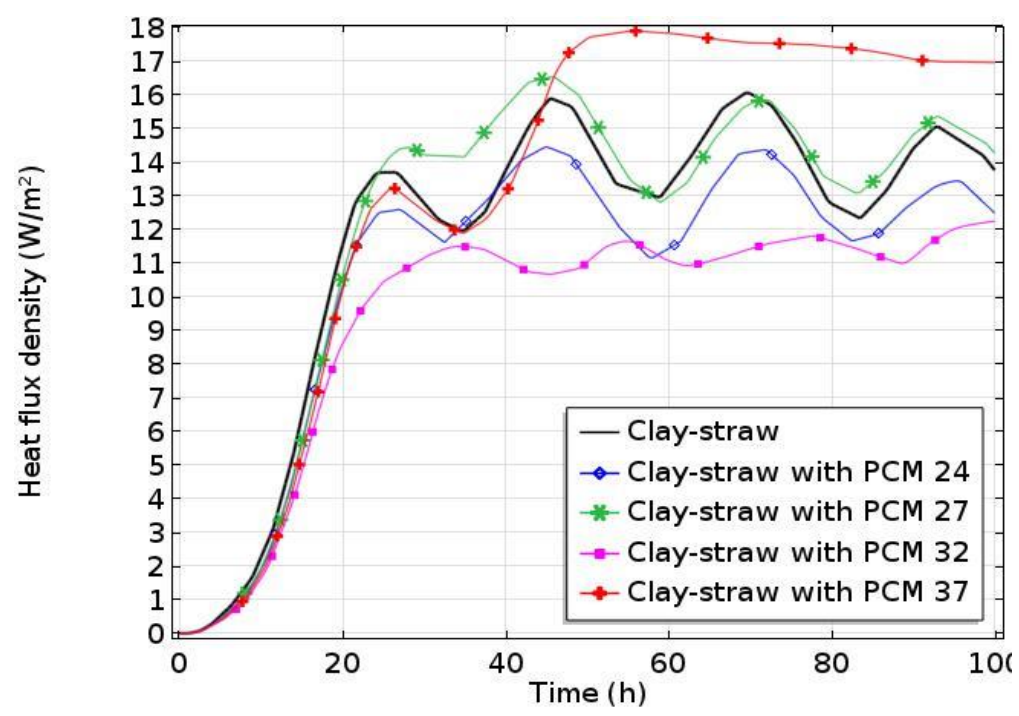

Fig. 5. heat flux density at the internal surface of clay-straw walls integrating different PCMs: (a) 0.5 $\mathrm{cm}$ thickness of PCM (b) $1 \mathrm{~cm}$ thickness of PCM(c) $2 \mathrm{~cm}$ thickness of PCM

After we have selected the most appropriate PCM for the Drâa-Tafilalet region, we proceed to the analysis of the optimal thickness at the PCM chosen. Figure 6 present the heat flux density at the internal surface of walls integrating different thicknesses of the PCM 32 layer. It can be seen that the heat flux density decreases as the thickness of the PCM 32 layer increases. Therefore, the optimal thickness is $2 \mathrm{~cm}$; it is noticed that the peak of this wall is different from the other walls. When the flux increases for all the walls, it decreases for the one with a thickness equal to $2 \mathrm{~cm}$ and the opposite. This difference is justified by the fact that the PCM 32 continues the phase change cycle correctly for the $2 \mathrm{~cm}$ thickness, whereas at the other thickness the PCM melts quickly and follows the variations of external conditions like insulating material. PCM 32 layer thickness equal to $2 \mathrm{~cm}$ can reach a maximum difference equal to $4 \mathrm{~W} / \mathrm{m}^{2}$. To understand the behavior of PCMs and their importance, a comparative study is presented in the following section. 


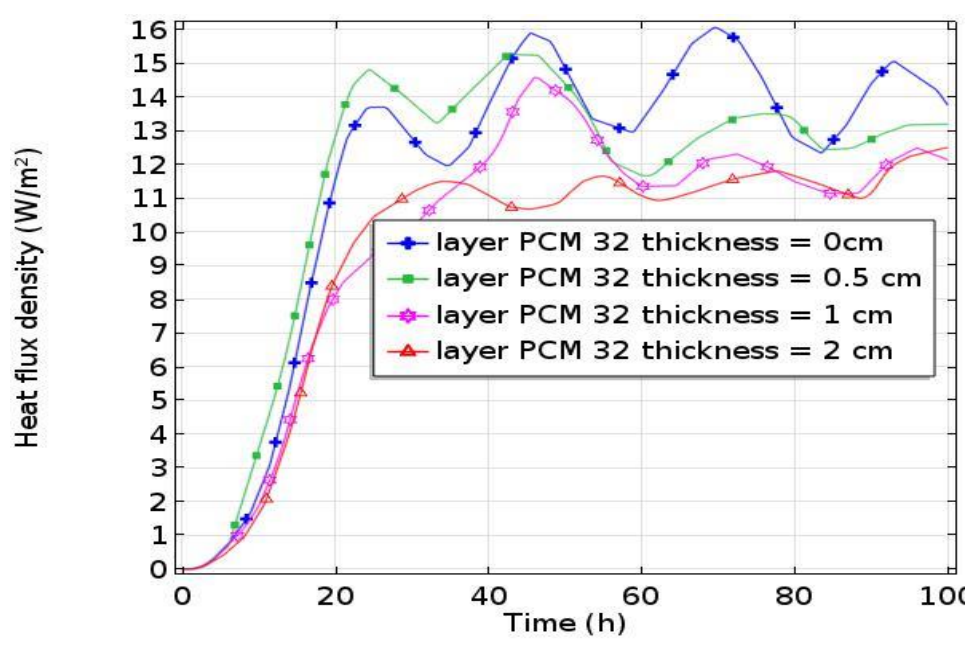

Fig. 6. Heat flux density $\left(\mathrm{W} / \mathrm{m}^{2}\right)$ at the internal surface of clay-straw walls integrating different thickness of PCM 32

\subsection{Comparison between integration of PCM into cement wall and clay-straw wall}

\subsubsection{Heat flux density and temperature comparison}

In order to analyze the integration of PCM in traditional clay-straw constructions instead of cement constructions; a comparative study is carried out in order to choose the most efficient construction. Figure 7 present the heat flux density $\left(\mathrm{W} / \mathrm{m}^{2}\right)$ and the temperature $\left({ }^{\circ} \mathrm{C}\right)$ at the internal surface of clay-straw walls and cement walls with PCM 32 and without it. The clay-straw construction reduces the heat flow density and temperature compared to cement construction by up to $37 \mathrm{~W} / \mathrm{m}^{2}$ and $5^{\circ} \mathrm{C}$ respectively. By integrating PCM32 in the cement wall, the heat flux density is reduced with a value up to $28 \mathrm{~W} / \mathrm{m}^{2}$ but it is still higher than the one generated by the clay-straw wall without PCM 32. For this reason, the ancient clay-straw constructions in the Drâa-Tafilalet region are important. By comparing the behavior of the cement wall and that of clay-straw incorporating PCM32, it can be seen that the behavior of the cement wall follows the variations of the external conditions as opposed to the clay-straw wall. For the last one, when the heat flux density increases outside, it decreases inside; which keeps the heat flux density (Fig.7- (a)) and the temperature (Fig.7- (b)) more or less constant because the PCM was partially liquid (partially solid); the phase change is performed.

a)

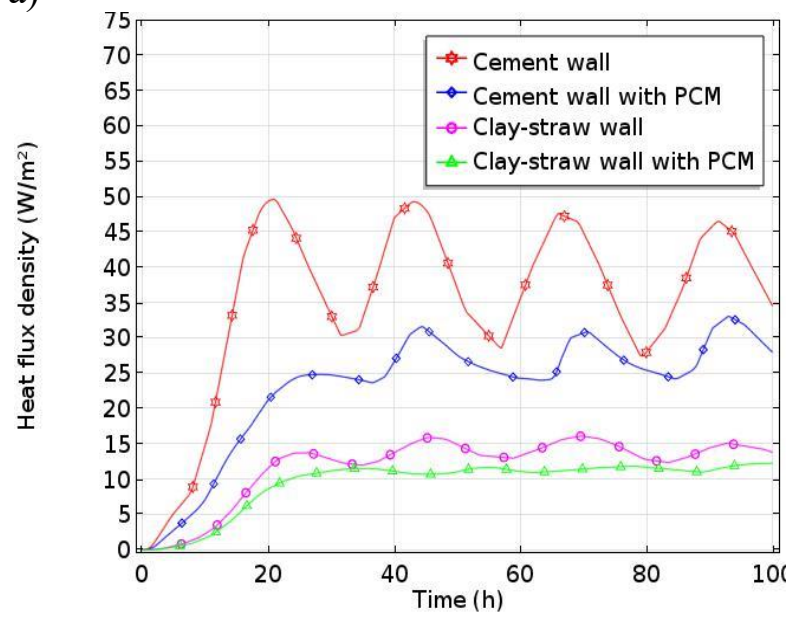

b)

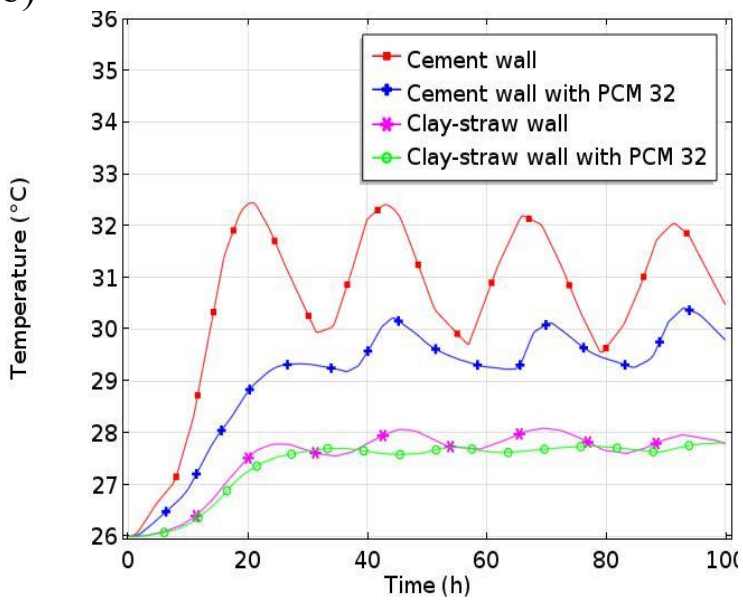

Fig. 7. The internal surface of clay-straw walls and cement walls with PCM 32 and without: (a) Heat flux density $\left(\mathrm{W} / \mathrm{m}^{2}\right)$; (b) Temperature $\left({ }^{\circ} \mathrm{C}\right)$ 


\subsubsection{Temperature Profile Comparison}

In order to understand the effect of the PCM integration in the building envelope, the temperature profile is presented in figure 8 . The temperature diffusion is more rapid in cement walls fig. 8 (a). It decreases by integrating the PCM32, which stores a large heat quantity inside fig.8 (b). In the opposite situation, the diffusion of temperature is reduced in clay-straw walls fig.8(c) and it is again reduced by integrating the PCM 32, which stores a large quantity of heat inside fig. 8 (d).

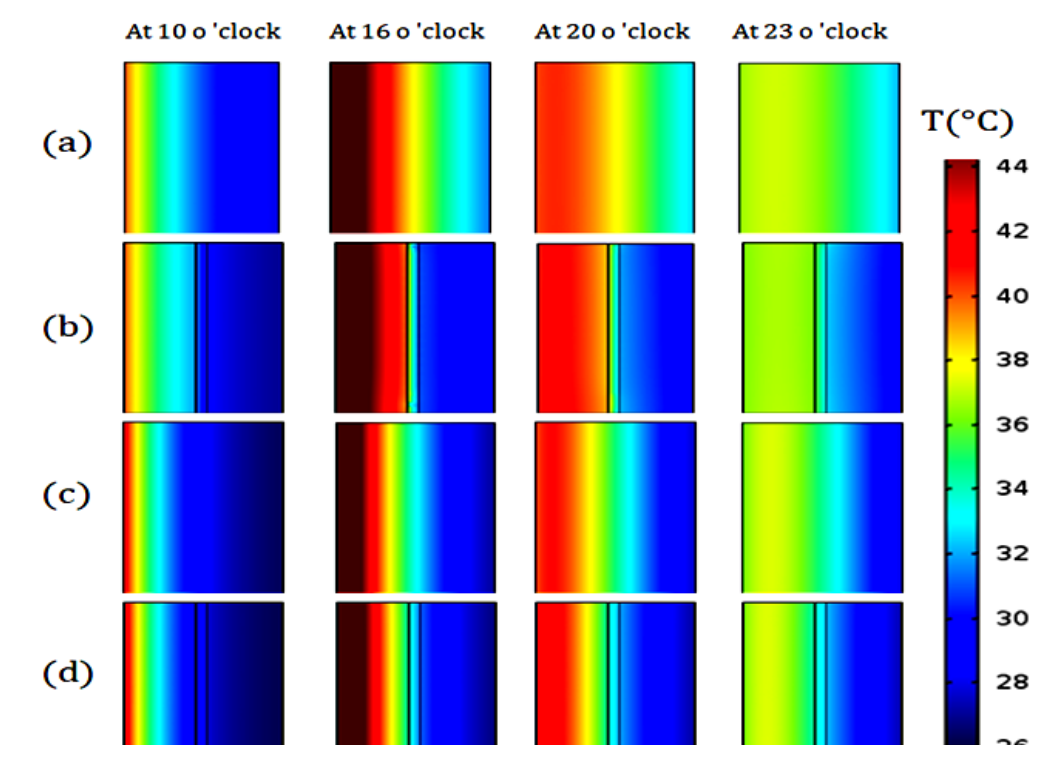

Fig.8. Comparison between the temperature Profile of different walls: (a) cement wall (b) cement wall with PCM 32 (c) clay-straw wall (d) clay-straw wall with PCM 32

\subsubsection{Heat flux reduction}

In this section, the reduction in flux density is estimated in percent. Figure 9 shows the heat flux density on the inside and outside of the walls exposed to the weather conditions of the Draa-Tafilalet region. The difference between the outside heat flux density is higher for the cement wall; it is twice as high as that of a clay-straw wall and depends on the properties of the materials. To better, analyze Figure 9, the percentage reduction in heat flux density $\mathrm{R}(\%)$ (Table 2 ) is calculated using the following relation:

$$
R(\%)=\frac{\varphi_{i(\text { without } P C M)}-\varphi_{i(\text { with } P C M)}}{\varphi_{i(\text { without } P C M)}} \times 100
$$

The integration of PCM 32 in clay-straw wall reduces heat flux density by $44.44 \%$ and by $40 \%$ in the cement wall. By using the clay-straw construction integrating PCM 32, instead of the cement product construction, the heat flux density is reduced by $80 \%$. 
a)

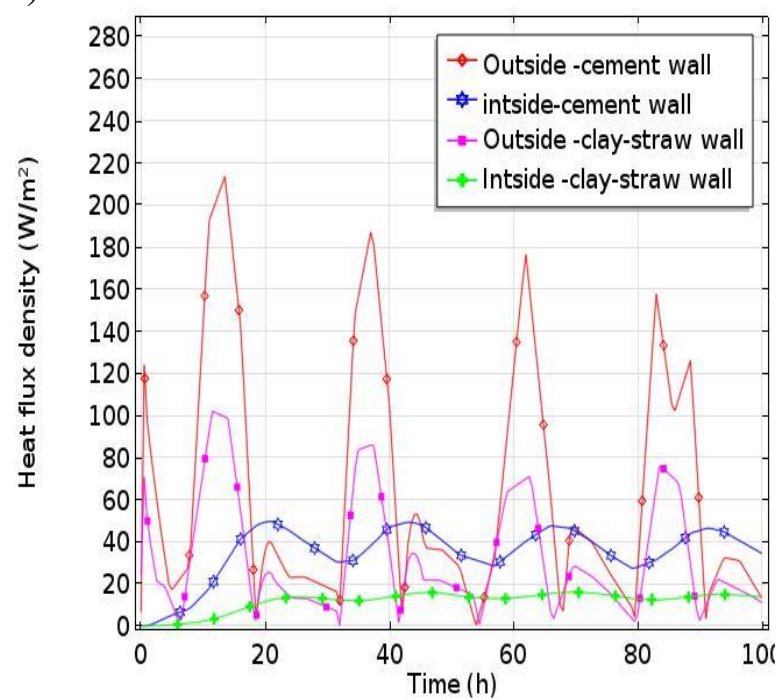

b)

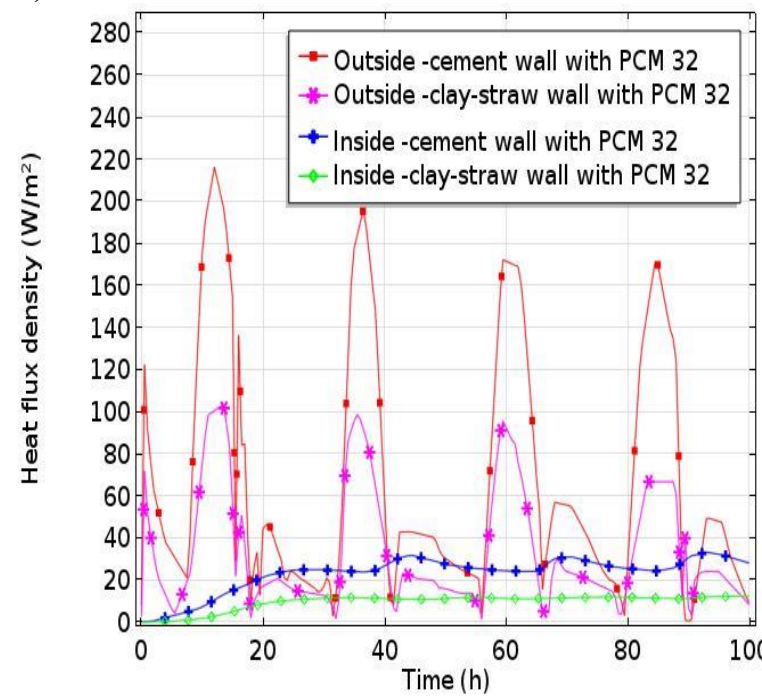

Fig. 9. The inside and outside heat flux density of clay-straw walls and cement walls: (a) Without PCM (b) With PCM 32

Table 2. Heat flux density reduction by integrating PCM 32

\begin{tabular}{|c|c|c|c|}
\hline \multicolumn{2}{|c|}{ Walls } & Cement wall & Clay-straw wall \\
\hline $\begin{array}{c}\text { Maximum inside heat flux } \\
\text { density }\left(\mathrm{W} / \mathrm{m}^{2}\right)\end{array}$ & without PCM 32 & 50 & 18 \\
\cline { 2 - 4 } & with PCM 32 & 30 & 10 \\
\hline \multicolumn{2}{|c|}{$\mathrm{R}(\%)$} & 40 & 44.44 \\
\hline
\end{tabular}

\section{Conclusion}

This paper investigated the integration of phase-change materials (PCM) in clay-straw walls of buildings located in Morocco's Drâa-Tafilalt region. The article deals with the climatic conditions of Errachidia city, corresponding to the Saharan thermal behavior heat flux density. Four PCMs with distinct median melting temperatures $\left(24{ }^{\circ} \mathrm{C}, 27{ }^{\circ} \mathrm{C}, 32^{\circ} \mathrm{C}\right.$, and $37^{\circ} \mathrm{C}$ ) are integrated into a clay-straw wall and compared to another without PCM. In terms of the reduction of heat flux peak, the PCM with a $\mathrm{T}_{\mathrm{m}}=32{ }^{\circ} \mathrm{C}$ median melting temperature is efficient in the Drâa-Tafilalet region. For all wall configurations, the heat flux at the inside surface of the wall, for the four days of July (28-31), was constant when the PCM was partially liquid (partially solid) and followed the outside conditions when the PCM was completely solid or liquid. By using the clay-straw construction integrating PCM 32 , instead of the cement product construction, the heat flux density is reduced by $80 \%$.

\section{References}

[1] S. Lu, J. Gao, H. Tong, S. Yin, X. Tang, and X. Jiang, "Model establishment and operation optimization of the casing PCM radiant floor heating system," Energy, vol. 193, p. 116814, 2020.

[2] G. Tuna and V. E. Tuna, "The asymmetric causal relationship between renewable and NON-

RENEWABLE energy consumption and economic growth in the ASEAN-5 countries," Resour. Policy, vol. 62, no. November 2018, pp. 114-124, 2019.

[3] M. Papież, S. Śmiech, and K. Frodyma, "Effects of renewable energy sector development on electricity consumption - Growth nexus in the European Union," Renew. Sustain. Energy Rev., vol. 113, no. July, p. 109276, 2019.

[4] H. Akeiber et al., "A review on phase change material (PCM) for sustainable passive cooling in building envelopes," Renew. Sustain. Energy Rev., vol. 60, pp. 1470-1497, 2016.

[5] S. Kaba, K. Achoubir, and A. Cheddadi, "An enhanced numerical approach for convection phase change problems: A solution of tin melting problem," Case Stud. Therm. Eng., vol. 18, no. October 2019, p. $100585,2020$.

[6] M. M. El Idi and M. Karkri, "Heating and cooling conditions effects on the kinetic of phase change of 
[7]

[11] P. Schossig, H. M. Henning, S. Gschwander, and T. Haussmann, "Micro-encapsulated phase-change materials integrated into construction materials," Sol. Energy Mater. Sol. Cells, vol. 89, no. 2-3, pp. 297-306, 2005.

[12] F. Kuznik, J. Virgone, and K. Johannes, "In-situ study of thermal comfort enhancement in a renovated building equipped with phase change material wallboard," Renew. Energy, vol. 36, no. 5, pp. 1458$1462,2011$.

[13] A. M. Borreguero, M. Luz Sánchez, J. L. Valverde, M. Carmona, and J. F. Rodríguez, "Thermal testing and numerical simulation of gypsum wallboards incorporated with different PCMs content," Appl. Energy, vol. 88, no. 3, pp. 930-937, 2011.

[14] A. Bontemps, M. Ahmad, K. Johanns, and H. Sallée, "Experimental and modelling study of twin cells with latent heat storage walls," Energy Build., vol. 43, no. 9, pp. 2456-2461, 2011.

[15] A. Castell, I. Martorell, M. Medrano, G. Pérez, and L. F. Cabeza, "Experimental study of using PCM in brick constructive solutions for passive cooling," Energy Build., vol. 42, no. 4, pp. 534-540, 2010.

[16] A. C. Evers, M. A. Medina, and Y. Fang, "Evaluation of the thermal performance of frame walls enhanced with paraffin and hydrated salt phase change materials using a dynamic wall simulator," Build. Environ., vol. 45, no. 8, pp. 1762-1768, 2010.

[17] M. A. Medina, J. B. King, and M. Zhang, "On the heat transfer rate reduction of structural insulated panels (SIPs) outfitted with phase change materials (PCMs)," Energy, vol. 33, no. 4, pp. 667-678, 2008.

[18] L. Royon, L. Karim, and A. Bontemps, "Thermal energy storage and release of a new component with PCM for integration in floors for thermal management of buildings," Energy Build., vol. 63, pp. 29-35, 2013.

[19] D. Li, Y. Wu, B. Wang, C. Liu, and M. Arıc1, "Optical and thermal performance of glazing units containing PCM in buildings: A review," Constr. Build. Mater., vol. 233, p. 117327, 2020.

[20] Z. Ben Zaid, A. Tilioua, I. Lamaamar, O. Ansari, H. Souli, and M. A. Hamdi Alaoui, "An experimental study of the efficacy of integrating a phase change material into a clay-straw wall in the Drâa-Tafilalet Region (Errachidia Province), Morocco," J. Build. Eng., vol. 32, no. July, 2020.

[21] A. Laborel-Préneron, C. Magniont, and J. E. Aubert, "Hygrothermal properties of unfired earth bricks: Effect of barley straw, hemp shiv and corn cob addition,” Energy Build., vol. 178, pp. 265-278, 2018.

[22] E. M. Alawadhi and H. J. Alqallaf, "Building roof with conical holes containing PCM to reduce the cooling load: Numerical study,” Energy Convers. Manag., vol. 52, no. 8-9, pp. 2958-2964, 2011.

[23] Z. Aketouane et al., "Energy savings potential by integrating Phase Change Material into hollow bricks: The case of Moroccan buildings," Build. Simul., vol. 11, no. 6, pp. 1109-1122, 2018.

[24] A. Joulin, Z. Younsi, L. Zalewski, S. Lassue, D. R. Rousse, and J. P. Cavrot, "Experimental and numerical investigation of a phase change material: Thermal-energy storage and release," Appl. Energy, vol. 88 , no. 7, pp. 2454-2462, 2011.

[25] R. Guechchati, M. A. Moussaoui, A. Mezrhab, and A. Mezrhab, "Reducing energy consumption of habitat located in eastern region of Morocco," Appl. Sol. Energy (English Transl. Geliotekhnika), vol. 48, no. 1, pp. 33-37, 2012.

[26] ISO 6946, "Building components and building elements - Thermal resistance and thermal transmittance - Calculation method. ISO - International Organization for Standardization.," vol. 0, 2007. ADEREE, "Règlement Thermique de Construction au Maroc - Version simplifiée," 2014. 